\title{
Letter
}

\section{Enantioselective Electroreductive Coupling of Alkenyl and Benzyl Halides via Nickel Catalysis}

Travis J. DeLano, and Sarah E. Reisman

ACS Catal., Just Accepted Manuscript • Publication Date (Web): 25 Jun 2019

Downloaded from http://pubs.acs.org on June 25, 2019

\section{Just Accepted}

"Just Accepted" manuscripts have been peer-reviewed and accepted for publication. They are posted online prior to technical editing, formatting for publication and author proofing. The American Chemical Society provides "Just Accepted" as a service to the research community to expedite the dissemination of scientific material as soon as possible after acceptance. "Just Accepted" manuscripts appear in full in PDF format accompanied by an HTML abstract. "Just Accepted" manuscripts have been fully peer reviewed, but should not be considered the official version of record. They are citable by the Digital Object Identifier (DOI®). "Just Accepted" is an optional service offered to authors. Therefore, the "Just Accepted" Web site may not include all articles that will be published in the journal. After a manuscript is technically edited and formatted, it will be removed from the "Just Accepted" Web site and published as an ASAP article. Note that technical editing may introduce minor changes to the manuscript text and/or graphics which could affect content, and all legal disclaimers and ethical guidelines that apply to the journal pertain. ACS cannot be held responsible for errors or consequences arising from the use of information contained in these "Just Accepted" manuscripts. 
Nickel-catalyzed reductive cross-coupling reactions have emerged as powerful methods for the formation of carbon-carbon bonds. ${ }^{1}$ Typically, these cross-electrophile couplings employ a superstoichiometric metal powder, often $\mathrm{Mn}^{0}$ or $\mathrm{Zn}^{0}$, as a reductant to turn over the Ni catalyst. Such methods enable the formation of valuable $\mathrm{C}\left(\mathrm{sp}^{2}\right)-$ $\mathrm{C}\left(\mathrm{sp}^{3}\right)$ bonds without pre-generation of sensitive organometallic reagents common to many traditional cross-coupling reactions. Reductive couplings can be rendered particularly useful when a chiral ligand is used to afford enantioenriched products. To this end, our lab has developed several asymmetric nickel-catalyzed reductive coupling reactions employing $\mathrm{Mn}^{0}$ or tetrakis $(N, N$ dimethylamino)ethylene (TDAE) as the stoichiometric reductant. 2,3

Reactions utilizing a heterogeneous metal reductant can suffer from capricious stirring effects, variability in metal activity based on source, batch,

and storage conditions, and the generation of excess waste. Several approaches have been reported for overcoming some of these inherent challenges. Most commonly, soluble organic reductants have been employed, though insoluble salts frequently precipitate from solution as the reactions progress. ${ }^{4}$ Metallaphotoredox reductive couplings have been reported by MacMillan, ${ }^{5}$ Lei, ${ }^{6}$ and Vannucci, ${ }^{7}$ with $\left(\mathrm{Me}_{3} \mathrm{Si}\right)_{3} \mathrm{SiH}, \mathrm{Et}_{3} \mathrm{~N}$, and triethanolamine serving as homogenous terminal reductants, respectively. In recent decades, electrochemistry has also been leveraged as a strategy for avoiding several of the issues associated with the use of superstoichiometric metal reductants.

Seminal reports from Durandetti, Nédélec, and Périchon describe the electroreductive nickelcatalyzed coupling of aryl bromides and iodides with a variety of activated alkyl electrophiles. ${ }^{8}$ An excess of alkyl halide was typically added slowly over the course of the reaction in order to minimize unproductive homocoupling. This reactivity was extended to the preparation of enantioenriched $\alpha$ aryl carboxylic acids through the use of a chiral auxiliary, providing two enantioenriched acids in 82 and $85 \%$ enantiomeric excess (ee) after cleavage of the auxiliary. ${ }^{9}$ Recently, three additional electroreductive nickel-catalyzed couplings have been disclosed, all employing unactivated alkyl electrophiles. Hansen and coworkers reported the coupling of aryl bromides with alkyl bromides, using reticulated vitreous carbon foam (RVC) as the cathode and $\mathrm{Zn}$ as a sacrificial anode, in an undivided cell. ${ }^{10}$ Bio and coworkers reported an electrochemical reductive coupling of aryl iodides 
with alkyl $N$-hydroxyphthalimide (NHP) esters in a divided cell, both in batch and in flow, with $\mathrm{Et}_{3} \mathrm{~N}$ as the terminal reductant. ${ }^{11}$ Loren and coworkers reported an electroreductive decarboxylative coupling of carboxylate salts and aryl iodides, proceeding through in situ generation of NHP esters. ${ }^{12}$ The photochemical and electrochemical methods reported to date all employ an excess of one of the electrophiles and form products that are either achiral or racemic - with the exception of the aforementioned auxiliary-based examples.
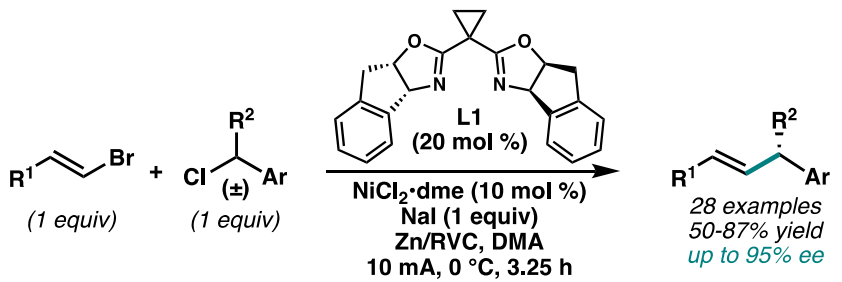

Figure 1. Nickel-catalyzed enantioselective electroreductive coupling. dme $=1,2-$ dimethoxyethane; DMA $=N, N$-dimethylacetamide.

Recognizing the benefits of electrochemistry, we sought to demonstrate that the enantioselective Nicatalyzed reductive alkenylation developed in our lab could be driven electrochemically. Whereas this transformation has been previously reported by our group with $\mathrm{Mn}^{0}$ as the terminal reductant, ${ }^{2 \mathrm{~b}}$ an electroreductive manifold would allow for the formation of valuable enantioenriched products without some of the difficulties encountered when using superstoichiometric metal powder reductants. Herein we report the first asymmetric electrochemical reductive cross-coupling (Figure 1).

Electrolysis of a solution of alkenyl bromide 1a $(1$ equiv), benzylic chloride 2 ( 1 equiv), $\mathrm{NiCl}_{2} \bullet \mathrm{dme}$ ( 10 mol \%), indanyl-substituted bis(oxazoline) ligand L1 (20 $\mathrm{mol} \%$ ), and NaI (1 equiv), in an undivided cell equipped with an RVC cathode and a sacrificial $\mathrm{Zn}$ anode, afforded $3 \mathrm{a}$ in $84 \%$ yield and $94 \%$ ee (Table 1 , entry 1$).{ }^{13}$ Electrolysis was highly efficient; the reaction was complete after application of the theoretically required amount of charge $(2.0 \mathrm{~F} / \mathrm{mol})$. Judicious selection of electrode materials proved essential for this reaction. When graphite was used in place of RVC foam (entry 2), significant drops in conversion, yield, and enantioselectivity were observed, as well as reduced mass recovery - a phenomenon previously observed by Baran and coworkers. ${ }^{14}$ Alternate sacrificial anode metals were also tested in place of $\mathrm{Zn}$. The reaction stopped early due to voltage overload $(12 \mathrm{~V})$ when either $\mathrm{Al}$ or $\mathrm{Mg}$ were used (entries 3 and 4). Under the standard reaction conditions, an Fe anode afforded coupled product 3a in 53\% yield and 95\% ee, with $28 \%$ remaining 2 (entry 5). When the reaction time was doubled (4 equiv $\mathrm{e}^{-}$), the $\mathrm{Fe}$ anode gave $3 \mathbf{a}$ in $70 \%$ yield and $94 \%$ ee (entry 6 ). ${ }^{15}$ Given that tuning the current allows for control over the rate of catalyst turnover, it is unsurprising that modulating the current has a significant effect on the outcome of the reaction. Doubling the current $(20 \mathrm{~mA})$ and halving the reaction time (entry 7), as well as halving the current $(5 \mathrm{~mA})$ and doubling the reaction time (entry 8 ) both afforded product in lower yields and enantiomeric excesses (77\% yield, $91 \%$ ee; and $61 \%$ yield, $93 \%$ ee, respectively).

Sodium iodide has been used by us and others as a reaction additive to increase yields in nickelcatalyzed reductive couplings. ${ }^{2 b, 16,17}$ In this reaction, $\mathrm{NaI}$ can serve a dual role as both reaction additive and electrolyte. Altering the identity of the electrolyte (TBAI, $\mathrm{TBAPF}_{6}, \mathrm{NaPF}_{6}$ ) resulted in reduced yields and enantioselectivities (entries 911). Lowering the loading of NaI or ligand, or increasing the temperature, were all detrimental to the reaction (entries 12-15). ${ }^{18}$ Control experiments confirmed that nickel and electrolyte were both essential (entries 16 and 17). Without ligand, the reaction afforded racemic product in 5\% yield (entry 18). When no current was passed, product was produced in $2 \%$ yield, likely due to slow reduction by the Zn electrode (entry 19). Although this reaction is thermodynamically favorable, the use of an external power source is required the overcome the overpotential of the cell. ${ }^{19}$

Table 1. Effects of Reaction Parameters. ${ }^{a}$

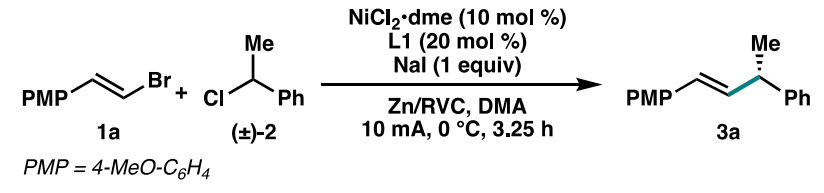

\begin{tabular}{cccc} 
entry & $\begin{array}{c}\text { deviation from standard } \\
\text { conditions }\end{array}$ & yield $(\%)^{b}$ & ee $(\%)^{c}$ \\
\hline 1 & None & 84 & 94 \\
& & & 2
\end{tabular}


2

3

4

5

6

7

8

9

10

11

12

13

14

15

16

17

18

19

${ }^{a}$ Reactions conducted on $0.6 \mathrm{mmol}$ scale. ${ }^{b}$ Determined by ${ }^{1} \mathrm{H}$ NMR integration versus $\mathrm{Bn}_{2} \mathrm{O}$ as an internal standard. 'Determined by SFC using a chiral stationary phase. ${ }^{d}$ Reaction stopped early due to voltage overload. TBA = tetra- $N$-butylammonium.

Having established efficient reaction conditions, we sought to explore the scope of alkenyl bromide electrophiles that could serve as competent coupling partners. Both styrenyl and alkyl-substituted alkenyl bromides coupled in high yields and enantioselectivities (Figure 2). Aryl groups bearing both electron-withdrawing groups (3c) and electrondonating groups (3a) were well tolerated. Several heterocyclic substrates ( $\mathbf{3 d}$ and $\mathbf{3 e}$ ) react smoothly, as well as both benzyl- and benzoyl-protected alcohols (3f, $\mathbf{3 g}$ ). Aryl boronate $\mathbf{1 b}$, free alcohol $\mathbf{1 h}$, and primary alkyl chloride $\mathbf{1 i}$ all coupled successfully to form products poised for direct elaboration (3b, 3h, 3i). Use of either $(3 R, 8 S)-\mathbf{L 1}$ or $(3 S, 8 R)-\mathbf{L 1}$ enabled the coupling of (-)-citronellal-derived alkenyl bromide $\mathbf{1 k}$ to give either the $(S, S)$ - or $(R, S)$-diastereomers of diene 3k, each with good diastereoselectivity.
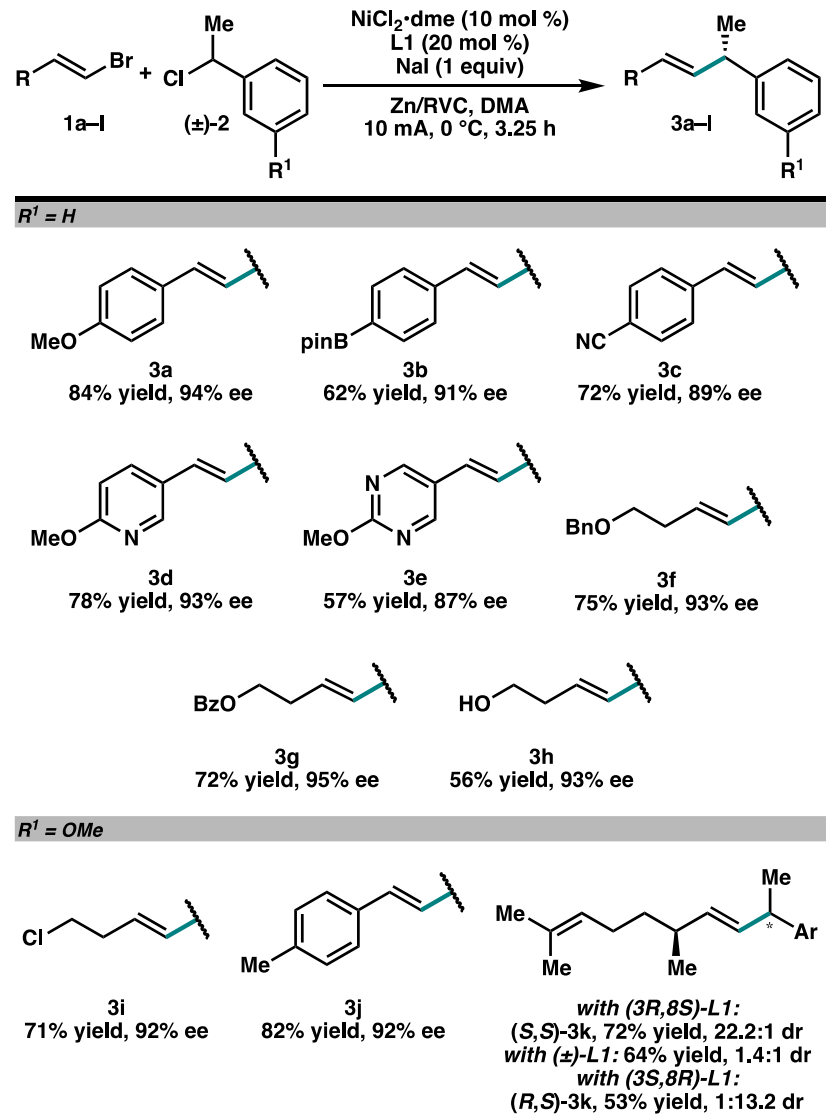

Figure 2. Scope of alkenyl bromides. Reactions conducted using $0.6 \mathrm{mmol}$ alkenyl bromide and 0.6 mmol benzyl chloride.

A variety of benzylic chlorides also proved to be competent coupling partners (Figure 3). Several halogenated arenes (4a-4d) were tolerated; unfortunately, substrates possessing aryl bromides suffered from competitive iodination and hydrodebromination. Whereas the o-methyl product 5e was obtained in lower yield and ee, the $o$-methoxy product was formed in good yield (5n). Extending the $\alpha$-phenyl alkyl chain from methyl to ethyl gave product $\mathbf{5 h}$ in comparable yield and excellent ee. Further increasing the steric bulk of this substituent resulted in a slight loss of ee (5i). The five- and six-membered ring products $5 \mathbf{j}$ and $5 \mathbf{k}$ were formed in good enantioselectivity, however a significant drop in selectivity was observed in the formation of 7-membered ring-containing product 51.

The starting benzylic chlorides were fully consumed after the reactions were run long enough to pass $2 \mathrm{~F} / \mathrm{mol}$, indicating excellent faradaic 
efficiencies in all cases. ${ }^{20}$ Construction of a larger reaction cell allowed for efficient scaleup of the reaction $(0.6 \mathrm{mmol}$ to $6.0 \mathrm{mmol})$, simply by increasing the current passed (10 $\mathrm{mA}$ to $100 \mathrm{~mA})$, to afford 3a on gram scale with only minor reductions in yield and enantioselectivity ( $83 \%$ yield, $91 \%$ ee). ${ }^{21}$

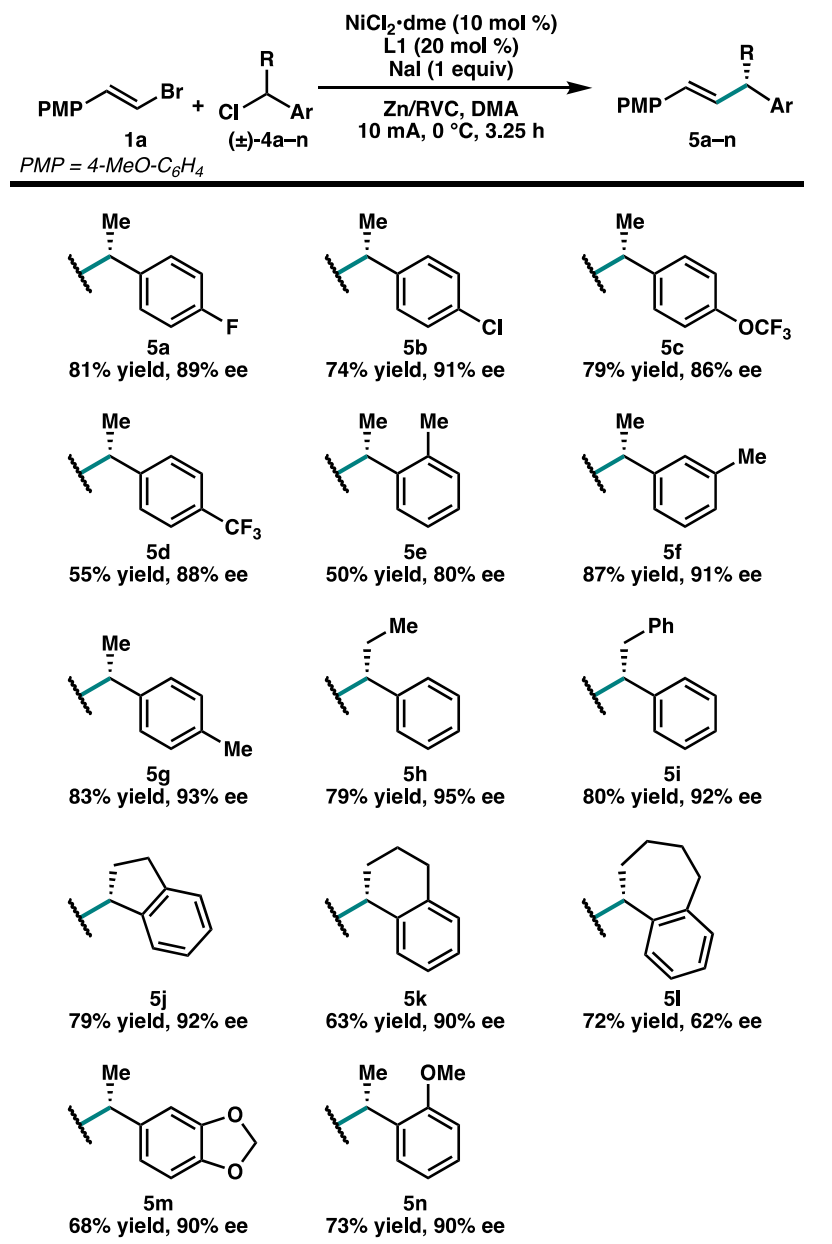

Figure 3. Scope of benzylic chlorides. Reactions conducted using $0.6 \mathrm{mmol}$ alkenyl bromide and 0.6 mmol benzyl chloride.

In summary, an efficient, enantioselective, electroreductive coupling of alkenyl bromides and benzyl chlorides has been developed. The use of electric current to turn over the nickel catalyst eliminates the need for superstoichiometric metal powder reductants. This method provides stereoconvergent access to compounds with allylic stereogenic centers, under mild conditions and with good selectivity. Additionally, this method does not require an excess of either of the coupling partners. Studies are ongoing to expand the use of electrochemical turnover in other nickel-catalyzed enantioselective reductive couplings.

\section{AUTHOR INFORMATION}

Corresponding Author

*reisman@caltech.edu

\section{Funding Sources}

No competing financial interests have been declared.

\section{ASSOCIATED CONTENT}

Supporting Information. Available free of charge on the ACS Publications website. Experimental procedures, characterization data $\left({ }^{1} \mathrm{H}\right.$ and ${ }^{13} \mathrm{C} N M R$, HRMS, FTIR) for all new compounds (pdf).

\section{ACKNOWLEDGMENT}

We thank Dr. Scott Virgil and the Caltech Center for Catalysis and Chemical Synthesis for access to analytical equipment. We thank Dr. Julie Hofstra for assistance with experimental design. Fellowship support was provided by the National Science Foundation (Graduate Research Fellowship, T.J.D. Grant No. DGE-1144469). S. E. R. is a Heritage Medical Research Institute Investigator. Financial support from the NIH (R35GM118191-01) is gratefully acknowledged.

\section{KEYWORDS}

Nickel, electrochemistry, enantioselective, crosscoupling, asymmetric catalysis

\section{REFERENCES}

1. (a) Knappke, C. E. I.; Grupe, S.; Gärtner, D.; Corpet, M.; Gosmini, C.; Jacobi von Wangelin, A. Reductive CrossCoupling Reactions between Two Electrophiles. Chem. Eur. J. 2014, 20, 6828-6842. (b) Everson, D. A.; Weix, D. J. CrossElectrophile Coupling: Principles of Reactivity and Selectivity. J. Org. Chem. 2014, 79, 4793-4798. (c) Weix, D. J. Methods and Mechanisms for Cross-Electrophile Coupling of Csp2 Halides with Alkyl Electrophiles. Acc. Chem. Res. 2015, 48, 1767-1775. (d) Wang, X.; Dai, Y.; Gong, H. Nickel-Catalyzed Reductive Couplings. Top. Curr. Chem. (Z) 2016, 374, 43.

2. (a) Cherney, A. H.; Kadunce, N. T.; Reisman, S. E. Catalytic Asymmetric Reductive Acyl Cross-Coupling: Synthesis of 
Enantioenriched Acyclic $\alpha, \alpha$-Disubstituted Ketones. J. Am. Chem. Soc. 2013, 135, 7442-7445. (b) Cherney, A. H.; Reisman, S. E. Nickel-Catalyzed Asymmetric Reductive CrossCoupling Between Vinyl and Benzyl Electrophiles. J. Am. Chem. Soc. 2014, 136, 14365-14368. (c) Kadunce, N. T.; Reisman, S. E. Nickel-Catalyzed Asymmetric Reductive CrossCoupling between Heteroaryl Iodides and $\alpha$-Chloronitriles. J. Am. Chem. Soc. 2015, 137, 10480-10483. (d) Poremba, K. E.; Kadunce, N. T.; Suzuki, N.; Cherney, A. H.; Reisman, S. E. Nickel-Catalyzed Asymmetric Reductive Cross-Coupling to Access 1,1-Diarylalkanes. J. Am. Chem. Soc. 2017, 139, 56845687. (e) Hofstra, J. L.; Cherney, A. H.; Ordner, C. M.; Reisman, S. E. Synthesis of Enantioenriched Allylic Silanes via NickelCatalyzed Reductive Cross-Coupling. J. Am. Chem. Soc. 2018, $140,139-142$.

3. For a review, see: Lucas, E. L.; Jarvo, E. R. Stereospecific and Stereoconvergent Cross-Couplings between Alkyl Electrophiles. Nature Rev. Chem. 2017, 1, 0065.

4. (a) Anka-Lufford, L. L.; Huihui, K. M. M.; Gower, N. J.; Ackerman, L. K. G.; Weix, D. J. Nickel-Catalyzed CrossElectrophile Coupling with Organic Reductants in NonAmide Solvents. Chem. Eur. J. 2016, 22, 11564-11567. (b) García-Domínguez, A.; Li, Z;; Nevado, C. Nickel-Catalyzed Reductive Dicarbofunctionalization of Alkenes. J. Am. Chem. Soc. 2017, 139, 6835-6838. (c) Xu, H.; Zhao, C.; Qian, Q.; Deng, W.; Gong, H. Nickel-Catalyzed Cross-Coupling of Unactivated Alkyl Halides Using Bis(Pinacolato)Diboron as Reductant. Chem. Sci. 2013, 4, 4022-4029.

5. (a) Zhang, P.; Le, C. "Chip"; MacMillan, D. W. C. Silyl Radical Activation of Alkyl Halides in Metallaphotoredox Catalysis: A Unique Pathway for Cross-Electrophile Coupling. J. Am. Chem. Soc. 2016, 138, 8084-8087. (b) Smith, R. T.; Zhang, Xiaheng, Rincón, J. A.; Agejas, J.; Materos, C.; Barberis, M.; García-Cerrada, de Frutos, O.; MacMillan, D. W. C. Metallaphotoredox-Catalyzed Cross-Electrophile Csp ${ }^{3}-\mathrm{Csp}^{3}$ Coupling. J. Am. Chem. Soc. 2018, 140, 17433-17438.

6. Duan, Z.; Li, W.; Lei, A. Nickel-Catalyzed Reductive CrossCoupling of Aryl Bromides with Alkyl Bromides: $\mathrm{Et}_{3} \mathrm{~N}$ as the Terminal Reductant. Org. Lett. 2016, 18, 4012-4015.

7. Paul, A.; Smith, M. D.; Vannucci, A. K. Photoredox-Assisted Reductive Cross-Coupling: Mechanistic Insight into Catalytic Aryl-Alkyl Cross-Couplings. J. Org. Chem. 2017, 82, 19962003.

8. (a) Conan, A.; Sibille, S.; d'Incan, E.; Périchon, J. NickelCatalysed Electroreductive Coupling of $\alpha$-Halogenoesters with Aryl or Vinyl Halides. J. Chem. Soc. Chem. Commun. 1990, 1, 48-49. (b) Durandetti, M.; Sibille, S.; Nédélec, J.-Y.; Périchon, J. A Novel Method of Arylation of $\alpha$ Chloroketones. Synth. Commun. 1994, 24, 145-151. (c) Durandetti, M.; Nédélec, J.-Y.; Périchon, J. Nickel-Catalyzed Direct Electrochemical Cross-Coupling between Aryl Halides and Activated Alkyl Halides. J. Org. Chem. 1996, 61, 17481755.

9. Durandetti, M.; Périchon, J.; Nédélec, J.-Y. Asymmetric Induction in the Electrochemical Cross-Coupling of Aryl
Halides with $\alpha$-Chloropropionic Acid Derivatives Catalyzed by Nickel Complexes. J. Org. Chem. 1997, 62, 7914-7915.

10. Perkins, R. J.; Pedro, D. J.; Hansen, E. C. Electrochemical Nickel Catalysis for $\mathrm{Sp}^{2}-\mathrm{Sp}^{3}$ Cross-Electrophile Coupling Reactions of Unactivated Alkyl Halides. Org. Lett. 2017, 19, 3755-3758.

11. Li, H.; Breen, C. P.; Seo, H.; Jamison, T. F.; Fang, Y.-Q.; Bio, M. M. Ni-Catalyzed Electrochemical Decarboxylative C-C Couplings in Batch and Continuous Flow. Org. Lett. 2018, 20, 1338-1341.

12. Koyanagi, T.; Herath, A.; Chong, A.; Ratnikov, M.; Valiere, A.; Chang, J.; Molteni, V.; Loren, J. One-Pot Electrochemical Nickel-Catalyzed Decarboxylative $\mathrm{Sp}^{2}-\mathrm{Sp}^{3}$ Cross-Coupling. Org. Lett. 2019, 21, 816-820.

13. The same reaction conducted under our previouslydisclosed conditions, using $\mathrm{Mn}^{0}$ as the terminal reductant, afforded product in $91 \%$ yield and $93 \%$ ee.

14. Horn, E. J.; Rosen, B. R.; Chen, Y.; Tang, J.; Chen, K.; Eastgate, M. D.; Baran, P. S. Scalable and Sustainable Electrochemical Allylic C-H Oxidation. Nature 2016, 533, 77-81.

15. When two RVC electrodes were employed with 3.0 equiv $\mathrm{Et}_{3} \mathrm{~N}$ as a redox mediator, no conversion to product was observed.

16. Colon, I.; Kelsey, D. R. Coupling of Aryl Chlorides by Nickel and Reducing Metals. J. Org. Chem. 1986, 51, 2627-2637.

17. Prinsell, M. R.; Everson, D. A.; Weix, D. J. Nickel-Catalyzed, Sodium Iodide-Promoted Reductive Dimerization of Alkyl Halides, Alkyl Pseudohalides, and Allylic Acetates. Chem. Commun. 2010, 46, 5743-5745.

18. Attempts to cool the reaction further presented issues with large amounts of water condensing on the exposed electrodes.

19. When the electrodes were connected directly with an ammeter between them, no current was observed with either an RVC or Ni foam cathode.

20. Full consumption of starting material was observed when 2 $\mathrm{F} / \mathrm{mol}$ were passed; the Faradaic efficiency of each reported example is equal to its chemical yield.

21. See Supporting Information for details.

TOC Graphic:

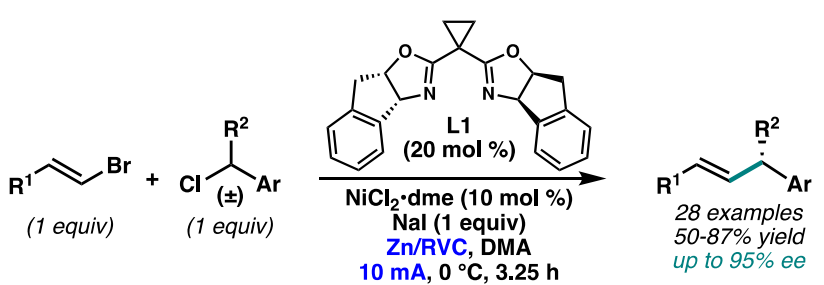

